\title{
Cumulative Risks and Promotive Factors for Chinese Adolescent Problem Behaviors
}

Hsing-Fang Hsieh ${ }^{\mathrm{a},{ }^{*}}$, Marc A. Zimmernan ${ }^{\mathrm{a}}$, Yange Xue ${ }^{\mathrm{b}}$, Jose A. Bauermeister ${ }^{\mathrm{a}}$, Cleopatra H.

Caldwell $^{\mathrm{a}}$, Zhenhong Wang ${ }^{\mathrm{c}}$, Yubo Hou ${ }^{\mathrm{d}, *}$

${ }^{a}$ University of Michigan, Ann Arbor, MI, USA

${ }^{\mathrm{b}}$ Mathematica Policy Research, Inc., Princeton, NJ, US

${ }^{\mathrm{c}}$ Shaanxi Normal University, Xi'an, China

${ }^{\mathrm{d}}$ Peking University, Beijing, China

*Corresponding author

\section{Hsing-Fang Hsieh ${ }^{\mathrm{a}, *}$}

Department of Health Behavior and Health Education, School of Public Health, University of Michigan, Ann Arbor, MI, USA

E-mail: fayenie@umich.edu

Phone: $734-272-3508$

Fax: 734-615-2317

Address: 1415 Washington Heights, Ann Arbor, MI. 48109-2029, United States

Marc A. Zimmerman ${ }^{\text {a }}$ E-mail: marcz@ umich.edu

Jose A. Bauermeister ${ }^{\mathrm{a}} \quad$ E-mail: jbauerme@ umich.edu

Cleopatra H. Caldwell ${ }^{\mathrm{a}} \quad$ E-mail: $\underline{\text { cleoc@ } \mathrm{umich} . e d u}$

Department of Health Behavior and Health Education, School of Public Health, University of Michigan, Ann Arbor, MI, USA

Address: 1415 Washington Heights, Ann Arbor, MI. 48109-2029, United States

\section{Yange Xue}

E-mail: YXue@ mathematica-mpr.com

Mathematica Policy Research, Inc., Princeton, NJ, USA

Address: P.O. Box 2393, Princeton, NJ 08543-2393

\section{Zhenhong Wang ${ }^{\mathrm{c}}$}

E-mail: wangzhenhong@ @snnu.edu.cn

School of Psychology, Shaanxi Normal University, Xi'an, China

Address: 199 South Road, Xi'an, Chang'an 710062, China

Yubo Hou d,"

Department of psychology, Peking University, Beijing, China

E-mail: houyubo@pku.edu.cn

Phone: 0086-10-6275338

Address: Department of Psychology, Peking University, Beijing, 100871 China. 


\begin{abstract}
The current study draws on resilience theory and examines the cumulative effects of multiple level risk and promotive factors on internalizing (e.g. psychological distress and self-acceptance) and externalizing outcomes (e.g. delinquency and substance use) among Chinese adolescents. The conceptual model includes factors across individual, peer, family, and community domains. A cross-sectional survey using self-reported questionnaires was conducted in two urban cities in China: Beijing and Xian ( $\mathrm{N}=1356 ; 52 \%$ female. Grades 7 to 12$)$. Structural equation modeling (SEM) analyses were conducted to test the conceptual models.
\end{abstract}

More cumulative risks were associated directly with more psychological distress, substance use and delinquency. The cumulative promotive factors provided compensatory effects of resiliency through decreased levels of psychological distress and problem behavior. Adolescents with more promotive factors reported higher self-acceptance. The study also provides evidence of developmental differences between middle-school and high-school adolescents in the compensatory model of resilience.

Key words: Problem Behaviors; Chinese Adolescents; Resiliency; Cumulative Risks; Cumulative Promotive Factors; Developmental Stage 


\section{Introduction}

Problem behaviors among Chinese youth are an emerging social and public health issue in China (Cheng, 1999; Cheng, 2008; Deng \& Roosa, 2007; Wang, 2006). With the marked increases in delinquent-type behaviors (Greenberger, Chen, Beam, Whang, \& Dong, 1999; Wong, 2001) and cigarette smoking (Hesketh, Lu, Jun, \& Mei, 2007; Anderson Johnson et al., 2006) among Chinese adolescents, increased emphasis is placed on examining potential susceptibility, promotive factors and their mechanisms affecting adolescents' psychological wellbeing and problem behaviors.

China is in the midst of rapid modernization and change in social relations (Wong \& Mok, 1995). Chinese youth have begun to absorb eagerly knowledge and values of Western culture while keeping their own cultural consciousness (Xiong, 2009). Moreover, researchers identified many similarities in promotive and risk factors of problematic behaviors between Chinese and U.S. adolescents (Jessor et al., 2003). Chinese adolescents have also begun to share more similar coping strategies that are typically more salient in Western society (Liu, Tein, \& Zhao, 2004; Shek, 1999, 2006c), making models of problem behavior and resiliency developed within the Western cultural context increasingly relevant to Chinese adolescence (Arthur, Hawkins, Pollard, Catalano, \& Baglioni, 2002). Based on the Western-developed theories and a resilience perspective, we investigated an array of problem behaviors by examining the cumulative effects of multiple-domain risk and promotive factors among Chinese adolescents.

\section{Theoretical Background}

Both Ecological Theory (Bronfenbrenner, 1986) and the Social Development Model (SDM) (Catalano \& Hawkins, 1996) support the rationale of including multiple-level factors in understanding problem behavior during childhood and adolescence. Bronfenbrenner (1986) 
suggested a socioecological framework to examine how contextual factors (e.g. family, school, peers, community, society, and culture) may shape adolescent behaviors. The framework included both intrapersonal and interpersonal aspects and the neighborhood characteristics that can interact together to influence the development of problem behaviors. The SDM takes into account risk factors as well as promotive factors to predict the development of prosocial or antisocial behaviors among adolescents (Catalano \& Hawkins, 1996). The SDM hypothesizes that children's attitude, beliefs, and behaviors are shaped by the social unit, such as family, peers, or neighborhoods, to which they are firmly bonded. In other words, the more bonds with antisocial units that a child has, the more likely the child will engage in problem behavior. On the other hand, pro-social bonds may help the child to have more prosocial attitudes and behaviors (Catalano \& Hawkins, 1996). Researchers who emphasize the social ecological perspective and the use of comprehensive theoretical models, therefore, generally examine adolescent problem behaviors by considering multiple factors in individual, family, peer, school, and neighborhood levels.

\section{Resiliency among Adolescents}

In addition, researchers have drawn growing attention on positive influences or promotive factors in youth development. Similar to their western counterparts, not all Chinese children exposed to risk develop internalizing or externalizing problems in the presence of adversity (Lee, Shek, \& Kwong, 2007). In a review of research literature on resiliency framework, Fergus and Zimmerman (2005) summarized the definition of promotive factors as the individual assets or contextual resources that help youth avoid the negative effects of risks.

Resiliency theory identifies two processes on how promotive factors play a role in helping youth to overcome the negative risk effects and positively improve the health and well- 
being (Fergusson, Vitaro, Wanner, \& Brendgen, 2007; Garmezy, Masten, \& Tellegen, 1984;

Luthar, Cicchetti, \& Becker, 2000; Rutter, 1987). The first process is explained in a compensatory model where promotive factors directly reduce the negative outcomes, such as psychological distress and problem behaviors, to compensate for the effect of risk exposure (Garmezy, et al., 1984). The second process is described in a risk-protective model where promotive factors interact with risk factors and buffer or moderate the negative influence of risk exposure (Rutter, 1985). Researchers have provided empirical evidence that supports both the compensatory and risk-protective models for understanding how risk and promotive factors are associated with substance use and delinquent behaviors (Newcomb \& Felix-Ortiz, 1992; Ostaszewski \& Zimmerman, 2006; Simons-Morton, Hartos, \& Haynie, 2004; Stoddard, et al., 2012; Van der Laan, et al., 2010; Wills, Vaccaro, \& McNamara, 1992).

Application of ecological models on resilience research suggests that multiple domains of influence for both risk and promotive factors are necessary. Ostaszewski and Zimmerman (2006) identified risk and promotive factors can be categorized into four ecological domains: 1) individual characteristics (e.g. self-acceptance, coping styles and skills, social skills, academic performance, violence victimization, hopelessness); 2) peer influences ( e.g. peer health-related behaviors, friends' support, friends' positive influence); 3) family relationships (e.g. parent-child relationship, parental support, parental monitoring, family conflicts); and 4) community characteristics (e.g. drug, alcohol, or cigarette availability in the community, availability of afterschool activities, community violence) (Ostaszewski \& Zimmerman, 2006).

\section{Multiple-level Risks and Promotive Factors among Chinese Adolescence}

Few researchers have started to emphasize the importance of including multiple-level risks and promotive factors in the effort of preventing problem behaviors among Chinese 
adolescents (Jessor et al., 2003; Shek, 2007; Wen et al., 2007). In a review article of substance abuse in Hong Kong, Shek (2007) noted that the social ecological understanding and the resilience perspective are keys for understanding Chinese adolescent problem behaviors. Shek also discussed several factors that predispose the adolescent substance abuse problem. Individual-level factors such as curiosity, lack of coping skills, underachievement and nonengagement at school are associated with adolescent substance use (Shek, 2006a; Shek \& Lee, 2004). Family-level factors such as the family structure (e.g. non-intact families, generally defined as families with both parents, as opposed to intact families where one or both parents are not present), parental absence or parental marital problems, and parenting problems may play a role in influencing children's development of substance use ( Ma, Yao, \& Zhao, 2013; Mak et al., 2010, Shek, 2006b; Shek, 2006c; Shek, 2007). Shek also noted that peer influence is a strong factor contributing to Chinese adolescent problem behaviors. In fact, he noted the effects of peer influence may interact with the larger social environment. The emerging subculture and virtual communication among adolescents, for example, may make children more vulnerable to negative interpersonal influences (Shek, 2007). Yet, most of the studies reviewed by Shek are conducted in Hong Kong, not mainland China. Although these risks and protective factors are mainly focusing on adolescents in Hong Kong, some similar factors have been examined in several studies in China. Wen et al. (2007) studies modifiable family and school environmental factors associated to teen smoking in China. The study indicated that smoking behaviors and attitudes of peers, parents, and supervising teachers as well as the school surroundings influence the individual smoking behaviors in different statuses (e.g. experimental smoking, regular smoking, or attempting to quit (Wen, et al., 2007). 
Furthermore, researchers noted that the emphasized family value and small family size (one family, one child) may be crucial and unique in their influences on adolescent problem behaviors in China, including smoking. Due to the single child policy, the Chinese children who do not have siblings may have norms and behaviors shaped largely by peers and other interpersonal relationships (Wen, et al., 2007). Although several specific contextual factors of problem behaviors among Chinese adolescents have been discussed by researchers, the empirical research literature that addresses multiple risks and promotive factors or the cumulative effects of these factors in the Chinese contexts is limited. In addition, few of the researchers used resiliency theory to guide the analysis and interpretation of their results. The Present study: Testing Cumulative Effects of Risks and Promotive Factors among Chinese

\section{Adolescents}

Most researchers studying adolescent resiliency have focused on single risk factors or promotive factors, for example, negative peer influence or parental-child attachment, rather than considering the cumulative effects of multiple factors (Ostaszewski \& Zimmerman, 2006). Most researchers that have examined multiple factors of problem behaviors, however, focused on only one or two contextual levels (Wen, et al., 2007). Yet, in the face of a particular constellation of risks within specific social contexts, a single aspect of promotive factors may not be sufficient to help youth overcome the effects of multiple risks (Rutter, 1987).

A primary goal of the present study was to conduct a more integrative analysis that tests the cumulative, cross-domain effects of risks and promotive factors among Chinese adolescents. The design of this study expands on previous research in the following aspects. First, our study considers Chinese adolescents' development across the individual, immediate environment (family, school, and peers), and larger social environment (community, society, cultural). 
Studies on youth problem behaviors that adopt social-ecological perspectives indicated that individuals exposed to an accumulation of risks in multiple domains, rather than a single domain, are more likely to develop negative outcomes later (Loeber, Slot, \& Stouthamer-Loeber, 2008; Stoddard, et al., 2012). Conversely, an accumulation of promotive effects lowers the probability of negative outcomes or weakens the effects of risk exposure (Ostaszewski \& Zimmerman, 2006; Stoddard, et al., 2012; Van der Laan, et al., 2010; Youngblade, et al., 2007). Our study examines the relationship between the cumulative risk factors, the cumulative promotive factors and the problem behaviors.

Second, most of the studies related to adolescent resiliency were conducted in western cultures and few researchers have examined resilience theory among Chinese adolescents (Arpawong et al., 2010; Lam, Lam, Shek, \& Tang, 2004; Peng et al., 2012; Shek, 2007; Yu, Lau, Mak, Zhang, \& Lui, 2011). The current study is one of the first studies that draw on resilience theory and examine the cumulative cross-domain effects on adolescent behaviors in China. A compensatory model of resilience for problem behaviors is tested with the cumulative effect of risks and promotive factors including individual, peer, family, and community domains.

Third, few researchers have addressed the developmental differences of how risks and promotive factors may influence psychological well-being and problem behaviors among Chinese adolescents (Jessor et al., 2003). Ma, Yao, and Zhao (2013) have examined the prevalence of externalizing problems among adolescents aged 12-17 in an eastern city of China and found that the behavioral problems increased with the age. Jessor and colleagues (2003) compared problem behavior (e.g. substance use and delinquency) and their protective and risk factors between adolescents from mainland China and adolescents from the United Sates. The results suggested that problem behavior was less prevalent and protective factors (e.g. models, 
controls, and supports) were scored higher in the Chinese sample than the U.S. sample.

Moreover, the results suggested gender, age, and family structure had significant effects only in the Chinese sample. These studies indicate the importance of further examining how developmental stages may influence the mechanisms among risks, promotive factors and problem behaviors. Therefore, we examined developmental differences between the middleschool and high-school adolescents (school grade) in our path models.

\section{Model Rationale and hypotheses}

Researchers have reported connections between psychological well-being and problem behaviors among U.S. adolescents (Byrne \& Mazanov, 2001; Fergus \& Zimmerman, 2005; Griffin, Botvin, Scheier, Epstein, \& Doyle, 2000; Repetto, Zimmerman, \& Caldwell, 2004a, 2004b; Repetto, Zimmerman, \& Caldwell, 2008; Schmeelk-Cone \& Zimmerman, 2003). In particular, Repetto, Zimmerman, \& Caldwell (2004a, 2004b, 2008) have provided evidence that depressive symptoms predicts later cigarette, alcohol, and marijuana use, while substance use did not predict later depressive symptoms. Self-appraisal may also play a role in the mechanisms of youth problem behaviors. Researchers have found that low self-appraisal leads to deviant behavior, which serves as a way to stimulate one's self-esteem (Bynner, O’Malley, \& Bachman, 1981; Donnellan, Trzesniewski, Robins, Moffitt, \& Caspi, 2005; Leary, Schreindorfer, \& Haupt, 1995; Rigby \& Cox, 1996). Conversely, positive self-acceptance or self-appraisal may assist adolescents with the adjustment process (Shek, 1997). These results suggest that psychological distress may mediate the negative effects of risks on adolescent substance use and delinquency. In the current study, we expect that higher cumulative risk will have both a direct effect on 
adolescent externalizing outcomes (e.g. delinquency and substance use) and an indirect effect through internalizing outcomes (e.g. psychological distress and low self-acceptance). In other words, a child with more exposure to cumulative risk factors may be at higher risk of having more psychological distress and low self-acceptance which would in turn exacerbate the risk of engaging in problematic behaviors among these adolescents. Moreover, higher exposure to cumulative risks may directly increase the level of a child's engagement in problematic behaviors (direct effect).

Cumulative promotive factors are tested in the current study with their compensatory effects on internalizing and externalizing outcomes. In the longitudinal study of cumulative risks and promotive factors, Ostaszeski and Zimmerman (2006) found that both risks and promotive factors have direct effects on polydrug use among adolescents. The compensatory effects of cumulative promotive factors were supportive both cross-sectionally and longitudinally, while the risk-protective effects were only evidenced cross-sectionally (Ostaszewski \& Zimmerman, 2006). Based on the literature of problem behaviors, cumulative factors and resiliency (Bowen \& Flora, 2002; Fergus \& Zimmerman, 2005; Ostaszewski \& Zimmerman, 2006; Stoddard, et al., 2012), we expect the cumulative promotive factors to be associated with less delinquent behaviors and substance use. More cumulative promotive factors are also hypothesized to be associated with less psychological distress and more self-acceptance. Figure 1 presents the compensatory effects of resiliency model of cumulative promotive factors. We then tested the modifying effects of school grade to examine how the paths in the conceptual model may differ between middle-school and high-school adolescents. 
Method

\section{Sample and Procedures}

The models were tested using survey data from three middle and high schools in two urban cities in China: Beijing and Xian. Participants in the study include 1356 students in Grades 7 to 12 from middle (44\%) and high schools (56\%). Approximately $48 \%$ of the respondents were boys and 52\% were girls. Experienced researchers in these two cities helped select participating schools based on characteristics such as diverse size, test scores, and social status. Youth were asked to complete questionnaires in school during a group administration in classrooms. Chinese research staff administered the data collection following the University of Michigan Institutional Review Boards (IRBS) protocol and the study was approved by the IRBS. Student assents were obtained before the survey was administrated. Schools participating in the survey study received a small stipend, but individual youth did not.

A questionnaire developed for the Flint Adolescent Study (e.g. Ostaszewski \&

Zimmerman, 2006) regarding risks and promotive factors of substance use, violent behavior, and delinquent behaviors was adapted for the current study. Chinese researchers in the study team helped with the revisions of the questionnaire to include culturally relevant terminology and contexts, and eliminated less relevant measures (e.g., sex-related items). We also conducted interviews with Chinese youth and their teachers about relative topics in this study to make sure the topics asked are proper within the cultural context. A Chinese researcher translated the questionnaire into Chinese and then a Chinese student translated it back into English. The U.S. team reviewed the translation and back-translation for accuracy. Internalizing and Externalizing Outcomes 
Internalizing outcomes were psychological distress and self-acceptance. We also measured substance use (e.g. smoking and drinking) and delinquency (violent behaviors and non-violent delinquent behaviors) as externalizing outcomes.

Psychological Distress. Depression $(\alpha=.91)$ and anxiety $(\alpha=.89)$ symptoms were each measured with six items (Derogatis \& Spencer, 1982). The 5-point rating scales asked youth to indicate how much they were bothered by each of 12 symptoms in the past week.

Self-acceptance $(\alpha=.73)$. Four items were used to assess self-acceptance (Newcomb, Huba, \& Bentler, 1986), each using a 5- point scale. The higher the score indicated the more selfacceptance. Three items were included in the final analyses of the study: how happy I am with myself, how generally pleased I am with myself, and how much I regard myself as successful. One question, how much I like myself was removed from the scale because the item has particular low standardized factor loading (-.09) compared to other items (.50 to .85) in the preliminary factor analysis of self-acceptance. In the model, we treat self-acceptance as a latent factor with the three items as indicators.

Substance use. Smoking and alcohol use were each represented on a single-item scale. Adolescents reported the frequency of alcohol use over the past 30 days $(1=0$ times; $2=1-2$ times; 3=3-5 times; 4=6-9 times; 5=10-19 times; 6=20-39 times; $7=40+$ times) and frequency of smoking over the past 30 days $(1=$ not at all; $2=$ less than one cigarette per day; $3=1-5$ cigarettes per day; $4=$ =about one-half pack per day; $5=$ about one pack per day; $6=$ about one and one-half packs per day; $7=$ over two packs per day). A variable for alcohol use was then created to sum up use in the past 30 days and during the 12 month $(1=$ never use in the life time, $2=$ never use in the past 12 month, 3 14 = the sum of 30-day use and 12-month use). Both of the scores of alcohol use and cigarette use were standardized for the analyses. 
Delinquency. The frequency of violent behavior $(\alpha=$.77) was measured with a 5-item, 5point scale. Similarly, the frequency of non-violent delinquent behavior $(\alpha=.88)$ was measured with an 8-item, 5-point scale. Due to the skewness of these dependent variables, each item was recoded into a dichotomous (never/ever) scale. If a student answered 1 (never) to a question, he or she would get a new score of 0 . If the student answered 2 to 5 in the original scale (ever), he or she will get a new score of 1. A sum of 8 items of non-violent delinquent behaviors (ranging from 0 to 8 ) and a sum of 5 items of violent behaviors (ranging from 0 to 5 ) were then obtained for the final analyses. The skewness of non-violent delinquent behaviors was improved to 4.52, and the skewness of violent behavior was improved to 3.37 .

\section{Risk factor and Promotive Factor Measures}

Cumulative measures of risk and promotive factors usually consist of several variables within each domain, with a number of indicators ranging from six (Dekovic, 1999) to over twenty indicators for risks and promotive factors (Bowen \& Flora, 2002). Based on the theories and findings from previous empirical studies, the current study selects indicators and assigned them as either promotive or risk factors based on the theory to each contextual domain (e.g. individual, family, peer, and neighborhood) (Arthur, et al., 2002; Hawkins, Catalano, \& Miller, 1992; Kumpfer, Olds, Alexanderson, Zucker, \& Gary, 1998; Ostaszewski \& Zimmerman, 2006; Petraitis, Flay, \& Miller, 1995). A preliminary analysis was then conducted to help us to include only the factors that were correlated with the outcomes in our sample.

Individual-level factors included four variables (two risks and two promotive factors) : being a victim of violence (Ostaszewski \& Zimmerman, 2006), perceived stress (Cohen, Kamarck, \& Mermelstein, 1983), perceived control over personal life (Cohen, et al., 1983), and orientation toward the future (Stein, Newcomb, \& Bentler, 1986). 
Peer-level factors included five variables (three risks and two promotive factors): friends who use alcohol or drugs (Ostaszewski \& Zimmerman, 2006; Stacy, Newcomb, \& Bentler, 1992), friends who cut/suspended/dropped out of school (Ostaszewski \& Zimmerman, 2006), friends’ aggressive or delinquent behavior (Ostaszewski \& Zimmerman, 2006), friends' support (Procidano \& Heller, 1983), and friends' positive activities and school influences (Stein, et al., 1986).

Parental/familial influences included four variables (two risks and two promotive factors): drug and alcohol use by adult raising the respondent (Moos \& Moos, 1981), misdeeds/misconduct by parents (Ostaszewski \& Zimmerman, 2006), ), parental support (Procidano \& Heller, 1983), and parental supervision (Arthur, Hawkins, Pollard, Catalano, \& Baglioni, 2002).

Community-level factors included four indicators (two risks and two promotive factors): alcohol use by non-familial adults in the life of the student, misdeeds/misconduct by non-familial adults in the life of the student (Moos \& Moos, 1981), neighborhood monitoring, and in-school and out-school activities. Table 1 presents the nine variables that were included in the cumulative risk factors by domain for the current study. Table 2 presents the eight variables that are included in the cumulative promotive factors by domain for the current study.

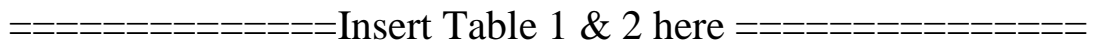

\section{Cumulative Risk and Promotive Factors Indices}

Cumulative indices were then computed by summing the standardized scores of promotive and risk factors under each domain, respectively, for each individual.

The individual level risk indicator variable, for example, included perceived stress and being a victim of violence. The sum of the two standardized scores of these variables was used as the 
individual-level indicator for the latent factor of cumulative risks. This method was used for other domains to create the total of four indicators for the cumulative risks and four indicators for the cumulative promotive factors.

\section{Data Analytic Plan}

We tested the compensatory model of resilience by conducting confirmatory latentvariable structural equation analysis with the EQS program (Bentler, 1995). Structural equation modeling (SEM) analysis allowed the examination of multiple dependent variables in a model and the relationships among the endogenous factors (Klem, 2000). SEM analysis also recognizes and takes into account the existence of measurement errors of predictive variables (Benbenishty, Astor, Zeira, \& Vinokur, 2002).

According to the recommendation of Raykov, Tomer, \& Nesselroade (1991), the goodness-of-fit indices was determined for each model using normed fit index (NFI), nonnormed fit index (NNFI), and comparative fit index (CFI). A widely used misfit index of root mean square error of approximation (RMSEA) was also reported. According to Hu \& Bentler (1999), fit indices that exceeded .90 and RMSEA misfit indices that is .06 or lower, respectively, are considered to support acceptable fit of the model (Hu \& Bentler, 1999).

We first conducted a SEM analysis of the compensatory model in Figure 1 with the total sample of the Chinese adolescent students. We conducted a multiple-group analysis comparing middle school and high school youth. The multiple-group analysis in SEM was a statistical procedure designed to examine the interaction effects because it tests whether group membership 
moderate the relations specified in a model (Kline, 2005, pp 289-311). Gender and parents' education were treated as control variables in the analyses.

Because our study is a cross-sectional design, temporal order cannot be established and therefore directionality of the effects was in question. The reverse model of the original theoretical model in Figure 1 was tested in order to exclude the possibility that the reverse model was a better fit for the data. In other words, delinquent behaviors and substance use were tested as independent factors, while cumulative risk factors and cumulative promotive factors were tested as dependent variables in the reverse model.

\section{Missing value and skewness}

Percentage of missing observations ranged across different variables. Missing observations for risk factors ranged from $0.1 \%$ at peer level to $0.4 \%$ at family level. Missing observations for promotive factors ranged from $0.1 \%$ at peer and family level to $0.4 \%$ at community level. For outcome variables, percentage ranged from a low of $0.2 \%$ missing for violent behavior to a high of $4.8 \%$ missing for alcohol use.

EQS estimates missing data by adjusting model parameter estimates using the maximum likelihood (ML) approach with robust standard error methodology. With the assumption that observations are missing at random (MAR), the ML approach ensures an unbiased estimates in the presence of missing data (Bentler, 1995, pp. 276). In order to address the skewness for our dependent variables, we used Robust methods provided by EQS 6.0. This method helps obtain a corrected $\chi 2$ statistic and standard errors so that they are more trustworthy for the data's nonnormality. The Yuan-Bentler scaled $\chi^{2}$ and Bentler-Bonett model fit indices were then reported in this study. 


\section{Results}

\section{Descriptive statistics on variables}

Table 3 presents the means and standard deviations of risk indices and promotive indices in each domain, internalized outcomes and externalized outcomes by middle- versus high- school adolescents in our sample. Overall, compared to high-school students, middle-school students reported lower scores in risk indices and slightly higher scores in promotive indices. Middle school students also reported lower psychological distress, less delinquency, less substance use and higher self-acceptance compared to students with high school students.

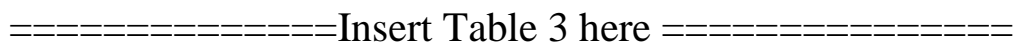

Table 4 provides bivariate correlations among the risk indices and outcome variables. Risk indices in each domain (individual, peer, family, and community) correlated with more anxiety, depression, non-violent delinquencies, violent behaviors, and substance use (correlations range from 0.17 to 0.54$)$; while risk indices was correlated with less self-acceptance (-0.06 to 0.24). Table 5 provides bivariate correlations among the promotive indices and outcome variables. Peer, family, and community domains of promotive indices correlated with less nonviolent delinquencies $(-0.08$ to -0.16$)$, violent behaviors $(-0.08$ to -0.17$)$, smoking $(-0.08$ to 0.14), and alcohol use (-0.07 to -0.17). Anxiety and depression were correlated with less selfacceptance $(-0.32$ and -0.38$)$, while they are both positively correlated with other outcome variables. Self-acceptance correlated with higher promotive indices (0.11 to 0.21$)$, less smoking behavior (-0.07), and less non-violent delinquency (-0.06). All the four kinds of problem behaviors correlated with each other, with correlations ranging from 0.20 to 0.65 . 


\section{Testing the Compensatory Model Based on Total Sample}

Figure 2 presents the results of the structural equation parameter estimation of the compensatory model of resilience of Chinese adolescent problem behaviors. The reverse model generated the same model fit as the original one; therefore, we adopted the original hypothesized model because it is supported by both theories and past research. The initial SEM analysis of the compensatory model did not obtain a good model fit [Yuan-Bentler scaled $\chi^{2}(153, \mathrm{~N}=1,349)=$ $675.50(\mathrm{p}<.001)$, Bentler-Bonett NFI $=.85$, Bentler-Bonett NNFI $=.83, \mathrm{CFI}=.88, \mathrm{RMSEA}=$ .05 , within $90 \%$ confidence interval], and the Lagrange Multiplier test (LM Test) in EQS indicated that an additional direct path from the error term of the indicator for individual risk index to the psychological distress factor would improve the model. (For an elaborated discussion of the respecification and re-estimated model based on the LM test, please refer to Bryne, 2008.) We made the modification because it was consistent with our original model as it indicates that individual risk contributes to psychological distress both indirectly as part of an overall cumulative risk factor and directly by itself. The results of the analysis after adding this parameter provided an acceptable fit to the total sample [Yuan-Bentler scaled $\chi^{2}(152, N=1,349)$ $=491.05(\mathrm{p}<.001)$, Bentler-Bonett NFI $=.89$, Bentler-Bonett NNFI $=.89$, CFI $=.92$, RMSEA $=.04$, within $90 \%$ confidence interval.] The overall model explained $54 \%$ of the variance in delinquent behaviors and $67 \%$ of the variance in substance use.

$==============$ Insert Figure 2 here $===============$ 
Higher cumulative promotive factors correlated with less cumulative risks $(r=-.25)$. After controlling for gender, school grade, and parents' education levels, the main contributor to both delinquent behaviors and substance use was cumulative risk factors $(\beta=0.71 ; 0.77$, respectively). Self-Acceptance was also associated with delinquent behaviors $(\beta=0.10)$, but not substance use. Cumulative risk influence was also found to be associated with more psychological distress $(\beta=0.38)$, while psychological distress was not associated with either delinquent behaviors or substance use at the significance level. No direct effect was found between cumulative risks and self-acceptance. Higher cumulative promotive factors, as expected, was linked with higher self-acceptance $(\beta=0.37)$, and lower psychological distress $(\beta=-0.17)$. Cumulative promotive factors had direct effect on delinquency behaviors $(\beta=-0.09)$, but did not have direct effect on substance use.

\section{Testing the Modifying Effects of School Grades}

To test the modifying effect of school grades, we conducted multiple-group analysis for middle school vs. high school samples. Prior to the multiple-group analysis, we assessed the measurement invariance across middle-school and high-school samples. We fitted the model into the two samples separately without specifying constraints and to see if the factor loading for each item was significant for each sample. We also obtained the baseline chi-square value and fit indices by computing model fit for the pooled sample of two groups (unconstrained multi-group model). The goodness-of-fit statistics related to this baseline model (Yuan-Bentler Scaled $\chi 2=$ $607.28 / 276, \mathrm{CFI}=.92, \mathrm{RMSEA}=.04)$ was compared to the constraint model we tested in the multiple-group analysis and revealed very little decrement in overall fit. The factor loading for 
each indicator was also significant for both middle- and high- school samples in the constrained and unconstrained models. Thus, we determined measurement invariance across the two groups.

We then proceeded to multi-group analysis by constraining the factor loadings, the paths, and the covariances to be equal (Benbenishty et al., 2002). The results produced acceptable fit to the data [Yuan-Bentler scaled $\chi^{2}(302, n$ middle school $=601, n$ high school $=752)=674.86, p<$ 0.001, and with Bentler-Bonett NFI $=.85$, Bentler-Bonett NNFI $=.89, \mathrm{CFI}=.91, \mathrm{RMSEA}=.04$, within $90 \%$ confidence interval.]

The next analysis procedure was to see if the goodness-of-fit could be improved significantly by releasing certain path constraints between the two groups in the model. We used the Lagrange Multiplier Test (LM Test) in the EQS software and the associated chi-square statistic $($ criterion $=3.84)$ and the probability value $($ criterion $=0.05)$ assigned to each constraint parameter to examine nonequivalence and define group differences (Benbenishty, et al., 2002). The chosen constraints to be released is expected to reveal large difference of the corresponding path between the two groups (Benbenishty, et al., 2002). In other words, when the path constraint was released, we found a statistically significant reduction in $\chi^{2}$, indicating that the difference of the specific path between the two groups is significant. In our compensatory model, three constraints corresponding to three paths were released: 1) the link between cumulative risks and delinquent behaviors, with $\chi^{2}$ reduced $\left.4.89(\mathrm{p}<.001) ; 2\right)$ the link between cumulative promotive factors and delinquent behaviors, with $\chi^{2}$ reduced $13.36(\mathrm{p}<.001)$; and 3$)$ the link between cumulative risks and psychological distress, with $\chi^{2}$ reduced $4.47(\mathrm{p}<.001)$ (See Figure 3. The paths released are in dashed lines). The results from the final model with the constraints released were: Yuan-Bentler scaled $\chi^{2}(299, n$ middle school $=601, n$ high school $=752)=647.55, p<$ 0.001, and with Bentler-Bonett NFI $=.86$, Bentler-Bonett NNFI $=.90, \mathrm{CFI}=.92, \mathrm{RMSEA}=.04$, 
within $90 \%$ confidence interval. The LM Test also suggested that $\chi 2$ could be improved by releasing two constraints for the factor loadings between the two groups: the factor loadings of an item measuring self-acceptance and an item measuring depression. Although this may indicate that the two items do not operate exactly the same way for the two groups, the fact that each item loaded significantly on its respective latent factor for both groups suggested that measurement models were basically the same across groups. We decided not to release the constraints for the factor loadings of these items in our structural model analysis.

The final results indicated that the relationship between cumulative risks and delinquent behaviors was modified by adolescents' school grade. The effects of cumulative risk on delinquent behaviors were weaker for high-school adolescents $(\beta=.64)$ compared to middle school adolescents $(\beta=.77)$ in our sample. The effect of cumulative promotive factors on reducing delinquent behaviors was also stronger among high-school adolescents $(\beta=-.17)$, compared to no significant effect among middle-school students ( $\beta=.01$, not significant). Similarities also existed for the two groups. Cumulative risk has similar direct effects on increasing substance use across the two age groups. Cumulative promotive factors had similar effects on decreasing psychological distress, increasing self-acceptance, and decreasing substance use across two age groups. The effects of internalizing outcomes (self-acceptance and psychological distress) on delinquent behaviors were also the same across the two age groups. All the coefficients and variance explained were indicated in Figure 3 for two groups.

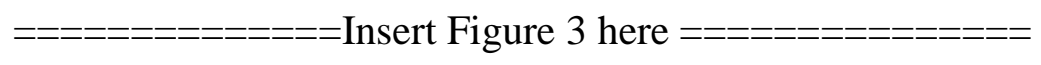
Post-hoc Analysis for the Mediating Effects 
In order to further probe the mediating mechanism, we formally tested the significance of mediating paths through psychological distress and self-acceptance for the total sample, followed by separate tests for high-school and middle-school samples. We used the Mplus software (Muthén \& Muthén, 2010). The results indicated that the mediating paths were not significant either in the total sample or in the subgroups. Among middle school students, however, the mediating effect of psychological distress between cumulative risk factors and delinquency was marginally significant with a two-tailed test (path coefficient $\beta_{\text {risks-distress-delinquency }}=.02, \mathrm{p}=.07$ ).

\section{Discussion}

The purpose of the study was to examine the cumulative effects and the relationship between risks and promotive factors across four contextual domains (e.g. individual, peer, family and community) on Chinese adolescent problem behaviors. Our findings are consistent with literature on the cumulative risk effects that children exposed to multiple risks are more likely to develop problem behaviors in adolescence than those with single-risk exposure (Guo, Hawkins, Hill, \& Abbott, 2001; Ostaszewski \& Zimmerman, 2006; Rutter, 1987; Stoddard, et al., 2012). Our findings also suggested that cumulative promotive factors play a role in protecting youth from problem behaviors through directly decreasing the psychological distress and problem behaviors.

\section{Compensatory Effect of Cumulative Promotive Factors}

The compensatory model of resiliency was supported by our study results. We hypothesized that cumulative promotive factors provide independent effects and in opposite direction of the risk effects on both internalizing and externalizing outcomes. Consistent with previous findings among American adolescents (Stoddard et al., 2013), our results suggested that 
higher levels of promotive factors were associated with lower levels of delinquency, including violent and non-violent behaviors. In addition, children with more promotive factors also tend to report higher self-acceptance and lower psychological distress, which is in line with our hypothesis that promotive factors are beneficial in adolescent development. Notably, although the compensatory effect of promotive factors on substance use was not significant in our first analysis with the total sample, this effect exists in the subsequent multiple-sample analysis. In the multiple-sample analysis between school grades, we found that higher level of promotive factors were associated with lower levels of substance use, with similar strength of correlations among middle- and high-school students (See Figure 3). The result is in line with Ostaszewski \& Zimmerman's (2006) findings that cumulative promotive factors have compensatory effects on adolescent substance use.

Our finding that higher self-acceptance was associated with slightly more delinquent behaviors was contradictory to our hypothesis, but was consistent with other studies of selfesteem and antisocial behaviors (David \& Kistner, 2000; Jang \& Thornberry, 1998; Vermeiren, Bogaerts, Ruchkin, Deboutte, \& Schwab-stone, 2004). Vermeiren et al. (2004), for example, found that subtypes of self-esteem (e.g. familial, academic, social, and personal security) present differently in adolescents involving aggressive antisocial behavior. Their result also suggested that high peer popularity, which serves as a subtype of self-concept, predicts violent offending. David and Kistner (2000) also found that positive self-perceptions were associated with elevated levels of aggression among $3^{\text {rd }}$ grade- to $5^{\text {th }}$ grade- students. Future research using longitudinal data may be able to further examine the direction of the positive relationship between selfacceptance and delinquency observed in our study. In addition, we did not find a significant effect from psychological distress to problem behaviors in our sample. Although the paths from 
psychological distress to delinquency and substance use were significant in our multiple-sample analysis, they were not strong associations. Perhaps our measurement of self-acceptance and psychological distress did not sufficiently capture psychological well-being that is salient for Chinese adolescents. Our post hoc test results did not offer formal support for the mediating effects of psychological distress and self-acceptance. This is not unexpected given the correlation coefficients between the two mediators and the dependent variables were somewhat small. Yet, the finding that psychological distress and self-acceptance were influenced by the cumulative risks and promotive factors in our study and had their combined influence on problem behaviors holds regardless of the lack of significant indirect effects. Future research with longitudinal data and more comprehensive measures for the internalizing behaviors among Chinese adolescents may be necessary to further understand this mechanism.

Moreover, it is worth noting that the variance explained by the compensatory model was comparably higher (54\% for delinquency and $67 \%$ for substance use) than previous studies that included only several factors in a single domain (Benner \& Kim, 2010; Nash, McQueen, \& Bray, 2005; Tompkins, Hockett, Abraibesh, \& Witt, 2011; Veronneau \& Dishion, 2010). The higher variance explained by our model may result from the cumulative measures of risks and promotive variables across multiple domains in our sample. Moreover, our preliminary analyses helped to include only the more relevant variables in the final analysis.

\section{The Moderating Effect of Developmental Stage}

Our study provides evidence of developmental differences between the early adolescence vs. middle-late adolescence in the risk compensatory effects of promotive factors. Although middle school students, compared to high-school students, reported lower scores in risk variables, our SEM analysis results suggested that they are more vulnerable to the risks 
associated with delinquency. Moreover, the compensatory effect of the promotive factors was stronger among high-school students (compared to no effect among middle-school students). A potential interpretation is that our measures of cumulative promotive factors were less relevant or helpful for middle school students than for high school students. To further investigate this difference in the compensatory effect of promotive factors, we reviewed the bivariate correlations between the individual, peer, family, and community level promotive indices and delinquency outcomes for middle school and high school students separately. We found that among middle school students, only family promotive indices were correlated with less delinquency. Among high school students, on the other hand, promotive indices for each ecological domain were correlated with less delinquency. Our findings suggest that risks and promotive factors may function differently across the developmental stages. In particular, family level promotive factors may be more influential than other individual and socio-ecological factors for the middle-school aged Chinese adolescents. As adolescents make the transition from middle school to high school, promotive factors from the individual, peer and community domains may become increasingly important. Our results also resonate with previous finding (Ma et al., 2013) that family level factors, such as family involvement and parental supervision, play the major role in the development of internalizing and externalizing behavior problems among Chinese adolescents.

Interestingly, while middle-school students may have comparably higher levels of externalizing problem behavior as a result of cumulative risks, high-school students in our sample tend to develop more internalizing problems when risks increase. It is important to consider the fact that the emphasis on academic achievement among Chinese adolescence (Liu et al., 2000) may limit the opportunities for students to engage in other activities, including 
delinquency and substance use. On the other hand, the continuous academic pressure, particularly higher among high-school students, may in turn influence their psychological wellbeing (Liu et al., 2000). Our findings, however, are consistent with past research (e.g., Jessor et al., 2003; Ma et al., 2013) and indicate that developmental issues are vital to consider in examining Chinese adolescent resilience.

\section{Cumulative Risk factors versus Cumulative Promotive factors}

Although researchers have reported support for a compensatory model of resiliency for problem behaviors when examining single risk and promotive factors, the effects of accumulation of risks may over-power the accumulation of promotive factors (Bowen \& Flora, 2002; Jessor, Van Den Bos, Vanderryn, Costa, \& Turbin, 1995; Newcomb \& Felix-Ortiz, 1992; Ostaszewski \& Zimmerman, 2006; Sameroff, Gutman, \& Peck, 2003; Zimmerman, Bingenheimer, \& Notaro, 2002). The findings in our Chinese sample are consistent with previous research that cumulative risk tends to produce stronger effects than the cumulative promotive factors when examining adolescent problem behavior. Yet, it is vital to note that even a small or modest protective effect by promotive factors may be crucial for outcomes that are difficult to influence such as adolescent substance use (Prentice \& Miller, 1992). Our study contributes to growing body of research on identifying risks and promotive factors that are culturally appropriate and relevant to Chinese adolescents.

\section{Factors Related to Contemporary Chinese Culture}

Several possible explanations may account for the smaller effect size of cumulative promotive factors in suppressing the negative effects of risk on problem behaviors in our study. First, while our cumulative measures included risk and promotive factors across different contextual domains, we may have missed some key factors that are important for problem 
behaviors among Chinese adolescents. A change in family structure in China as a result of economic development was reported (Grant \& Hutton, 2011). The rise of the number of nuclear families in China due to the one family, one child policy and the increasing number of both parents leaving their rural homes to work in the city contribute to a change of family structure. The children of parents who migrate to cities for work are called left-behind children (China Labor Bulletin, 2013). The China Labor Bulletin (2013) indicates that these children, estimated to be 61 million under the age of 18 , are faced with many difficulties and risks that may increase their involvement in problem behaviors including reduced supervision, limited parental support, and discrimination from majority institutions. As a result, researchers have noted a growing trend that children are being raised by their grandparents in both urban and rural China (Chen, Liu, \& Mair, 2011). The influences and parenting styles of grandparents may be an emerging factor for healthy youth development in China (Grant \& Hutton, 2011; Haddad, Chen, \& Greenberger, 2011). In particular, the differences between grandparents and parents in parenting styles, supervision, warmth provided to children, and discrimination they may face need to be addressed in future research in how they may have an effect on adolescent development.

Moreover, many adolescents in China have no siblings due to the policy of one family, one child. These adolescents may be under greater influence by peers and other important nonparental adults (Haddad, et al.), and they may have fewer opportunities to practice interpersonal skills than those with siblings (Haddad, et al., 2011; Shek, 2007; Wen, et al., 2007). Wen et al. (2007), for example, have found peers have significant influence on adolescents smoking in China, and suggested that the result may be attributed to the shared social and school environment of peers and the fact that many Chinese students have no siblings. The small family size may also bring both positive and negative influences into the youth development in China, 
including problem behaviors. On the one hand, children may get more parental attention and monitoring and thus they are less likely to engage delinquency or substance use. On the other hand, however, some parents or grandparents may overindulge their children, or focus too much on academic excellence at the expense of value development (Shek, 2007; Wen, et al., 2007).

The change of youth subculture that creates different peer relationships has been noted by researchers for their influence on the youth development in China (Grant \& Hutton, 2011; Shek, 2007; Wen, et al., 2007). For some adolescents, the online social networks that are shared particularly by peers may become a main source of interpersonal communication other than school settings (Shek, 2007). The limited spaces and places for recreation activities provided by the community may also contribute to the increased number of adolescents reporting being lonely or pressured by conflicting ideologies (Grant \& Hutton, 2011, pp. 10). Thus, to better understand problem behaviors among Chinese adolescents, future research that addresses the risk and promotive factors in parental absence, grandparents' or other adults' influences, interpersonal skills, and emerging youth subcultures may be particularly helpful.

In future studies, it would be beneficial to include promotive factors that are particularly relevant to Chinese adolescents. In China, for example, teachers are responsible for both students' academic instruction and their social, behavioral and daily life activities (Chen et al, 2000, Grant \& Hutton, 2011, Wen, et al., 2007). Wen et al (2007) found that teachers' smoking behaviors and attitudes may have direct and indirect effect on students' smoking behavior. Moreover, factors such as self-efficacy for avoiding smoking or drinking (Nash, et al., 2005), being taught smoking-related knowledge, the anti-tobacco school atmosphere (Wen, et al., 2007), and the availability of tobacco, alcohol and other drugs in China (Cheng, 1999; Cheng, 2008) may be more relevant for Chinese adolescents substance use. Unfortunately, we did not have these data 
to include in our cumulative index. Future research on resilience among Chinese youth at risk for substance would benefit from including this type of social influence information.

\section{Limitations of the study}

Some limitations should be noted to temper interpretation of the results. First, while cross-sectional data may provide us a snapshot of the associations and interactions between risks, promotive factors, and problem behaviors, longitudinal data will help the interpretation of causality and the mediating effects of psychological distress and self-acceptance. Further study considering longitudinal effects of cross-domain cumulative factors will further contribute to better understanding the mechanisms in which risk and promotive factors operate overtime.

Second, the approach of using cumulative indices equates all the component variables, but they may have differential effects. Some risk and promotive factors, therefore, may have stronger or weaker effects depending on the outcome studied. Further research that considers weighting of individual variables in a cumulative index may be useful for identifying particularly influential factors and better predict their cumulative effects on adolescent internalizing and externalizing behaviors. A combination of longitudinal analysis with more nuanced strategies of adding up the effects of various promotive factors could provide a useful approach to understand the cross-domain effects for different developmental stages (Zimmerman et al., 2013).

Third, the study relied on a self-report survey that only obtained the adolescents' subjective perspectives. With the emerging emphasis on examining the effect of contextual factors and interpersonal factors on adolescent problem behaviors, future research would benefit from incorporating both subjective and objective measures of the social contexts. Reports obtained from parents, other family members (such as grandparents), peers, and teachers would provide a more comprehensive assessment of risk and promotive factors and help inform how 
social contexts play a role in adolescents' psychological and behavioral health. Furthermore, the samples were collected within two Chinese cities, Beijing and Xian, which limits the generalizability of the results as they may be less relevant for youth in rural areas or in other urban areas of China that may have somewhat different local values, norms, and cultures.

Finally, the risk and promotive factors included in the current study may not be the most culturally appropriate for Chinese adolescents. Although this first study using a cumulative approach to understand how risks and promotive factors is useful, further work focusing on issues tailored for Chinese culture is necessary. We acknowledge that the overall model fit was not ideal. While the measurement properties of the constructs modeled in this study were examined and acceptable, it is likely that an inclusion of culturally relevant items such as influences of grandparents or teachers would improve the model fit. The risk and promotive factors selected in this study, however, were based on a review of theories and the empirical research in the literature based on a western perspective. Yet, the measures used in this study were also vetted by our Chinese colleagues before we implemented data collection. Nevertheless, most of the research on adolescent resiliency and the cumulative effects of factors are conducted within the western cultures, but our study expanded this program of research to examine how resilience theory can be applied in Chinese culture.

\section{Implications for Research and Practice}

The study draws on a theoretical framework and adopts analytic methods that allow an in-depth examination of resilience models that apply to Chinese adolescents. Resilience research provides a strengths-based perspective that focuses on identifying assets and resources to help adolescents overcome or alleviate negative risk effects. Our findings are consistent with previous resilience research using cumulative risks and promotive factors among Western adolescents 
(Ostaszewski \& Zimmerman, 2006; Stoddard et al., 2012). Although the exposure to multiple risks can be challenging for adolescents to overcome (Sameroff \& Rosenblum, 2006), our results suggest that cumulative promotive factors may operate in a compensatory way for mitigating the negative effects for Chinese adolescents (Ostaszewski \& Zimmerman, 2006; Stoddard et al., 2012; Zimmerman et al., 2013). This study also provides evidence of developmental differences on the compensatory model of resilience, indicating prevention approaches that consider developmental stages may be necessary to address Chinese adolescent problem behaviors. This was one of the few studies using a cumulative approach to understand risk and promotive factors associated with Chinese adolescent development. The results are promising and indicate that the application of resiliency theory can provide a useful guide for future research on Chinese adolescent development. 


\section{Reference}

Anderson Johnson, C., Palmer, P. H., Chou, C.-P., Pang, Z., Zhou, D., Dong, L., ... Unger, J. B. (2006). Tobacco use among youth and adults in Mainland China: the China Seven Cities Study. Public health, 120(12), 1156-69. doi:10.1016/j.puhe.2006.07.023

Arpawong, T. E., Sun, P., Chang, M. C.-C., Gallaher, P., Pang, Z., Guo, Q., ... Unger, J. (2010). Family and personal protective factors moderate the effects of adversity and negative disposition on smoking among Chinese adolescents. Substance use \& misuse, 45(9), 1367-89. doi:10.3109/10826081003686041

Arthur, M. W., Hawkins, J. D., Pollard, J. A., Catalano, R. F., \& Baglioni, A. J., Jr. (2002). Measuring risk and protective factors for substance use, delinquency, and other adolescent problem behaviors. The Communities That Care Youth Survey. Eval Rev, 26(6), 575-601.

Benbenishty, R., Astor, R. A., Zeira, A., \& Vinokur, A. D. (2002). Perceptions of violence and fear of school attendance among junior high school students in Israel. Social Work Research, 26(2), 7187.

Benner, A. D., \& Kim, S. Y. (2010). Understanding Chinese American Adolescents' Developmental Outcomes: Insights From the Family Stress Model. J Res Adolesc, 20(1), 1-12.

Bentler, P. M. (1995). EQS structural equation manual. . Los Angeles: BMDP Statistics Software.

Bowen, N. K., \& Flora, D. B. (2002). When is it appropriate to focus on protection in interventions for adolescents? Am J Orthopsychiatry, 72(4), 526-538.

Bronfenbrenner, U. (1986). Ecology of the family as a context for human development: Research Perspectives. . Developmental Psychology, 22(6), 723-742.

Bynner, J. M., O’Malley, P. M., \& Bachman, J. G. (1981). Self-esteem and delinquency revisited. Journal of Youth and Adolescence, 10(6), 407-441. doi:10.1007/BF02087937

Byrne, D., \& Mazanov, J. (2001). Self-esteem, stress and cigarette smoking in adolescents. Stress and Health, 110(March 2000), 105-110.

Byrne, B. M. (2008). Testing for multigroup equivalence of a measuring instrument: A walk through the process. Psicothema, 20(4), 872-882.

Catalano, R., \& Hawkins, J. (Eds.). (1996). The social development model: a theory of antisocial behavior. New York, NY: Cambridge University Press.

Chen, F., Liu, G., \& Mair, C. (2011). Intergenerational ties in context: Grandparents caring for grandchildren in China. Social forces, 90(2), 1-22. doi:10.1093/sf/sor012.

Chen, F., Short, S., \& Entwisle, B. (2000). The impact of grandparental proximity on maternal childcare in China. Population Research and Policy Review, (19), 571-590.

Cheng, T. O. (1999). Teenage smoking in China. J Adolesc, 22(5), 607-620.

Cheng, T. O. (2008). Adolescent smoking in China. Int J Cardiol, 126(1), 1-2. 
China Labour Bulletin (2013, June 27). Migrant workers and their children. China Labour Bulletin. Retrieved from http://www.clb.org.hk/en/content/migrant-workers-and-their-children

Cohen, S., Kamarck, T., \& Mermelstein, R. (1983). A global measure of perceived stress. J Health Soc Behav, 24(4), 385-396.

Dekovic, M. (1999). Risk and protective factors in the development of problem behavior during adolescence. Journal of Youth and Adolesence, 28(6), 667-685.

Deng, S., \& Roosa, M. W. (2007). Family influences on adolescent delinquent behaviors: applying the social development model to a Chinese sample. Am J Community Psychol, 40(3-4), 333-344.

Derogatis, L. R., \& Spencer, P. M. (1982). The Brief Symptom Inventory (BSI): Administration and scoring procedures. . Baltimore: Division of Medical Psychology: John Hopkins University School of Medicine.

Donnellan, M. B., Trzesniewski, K. H., Robins, R. W., Moffitt, T. E., \& Caspi, A. (2005). Low selfesteem is related to aggression, antisocial behavior, and delinquency. Psychological science, 16(4), 328-35. doi:10.1111/j.0956-7976.2005.01535.x

Fergus, S., \& Zimmerman, M. A. (2005). Adolescent resilience: a framework for understanding healthy development in the face of risk. Annu Rev Public Health, 26, 399-419.

Fergusson, D. M., Vitaro, F., Wanner, B., \& Brendgen, M. (2007). Protective and compensatory factors mitigating the influence of deviant friends on delinquent behaviours during early adolescence. $J$ Adolesc, 30(1), 33-50.

Garmezy, N., Masten, A. S., \& Tellegen, A. (1984). The study of stress and competence in children: a building block for developmental psychopathology. Child Dev, 55(1), 97-111.

Grant, J., \& Hutton, A. (2011). Supporting adolescents in a rapidly urbanising China. Contemp Nurse, $40(1), 5-14$.

Greenberger, E., Chen, C., Beam, M., Whang, S.-M., \& Dong, Q. (1999). The Perceived Social Contexts of Adolescents' Misconduct: A Comparative Study of Youths in Three Cultures. Journal of Research on Adolescence, 10(3), 365-88.

Griffin, K. W., Botvin, G. J., Scheier, L. M., Diaz, T., \& Miller, N. L. (2000). Parenting practices as predictors of substance use, delinquency, and aggression among urban minority youth: Moderating effects of family structure and gender. Psychology of Addictive Behaviors, 14(2), 174-184. doi:10.1037//0893-164X.14.2.174

Guo, J., Hawkins, J. D., Hill, K. G., \& Abbott, R. D. (2001). Childhood and adolescent predictors of alcohol abuse and dependence in young adulthood. J Stud Alcohol, 62(6), 754-762.

Haddad, E., Chen, C., \& Greenberger, E. (2011). The role of important non-parental adults (VIPs) in the lives of older adolescents: a comparison of three ethnic groups. J Youth Adolesc, 40(3), 310-319.

Hesketh, T., Lu, L., Jun, Y. X., \& Mei, W. H. (2007). Smoking, cessation and expenditure in low income Chinese: cross sectional survey. BMC public health, 7, 29. doi:10.1186/1471-2458-7-29 
Hu, L., \& Bentler, P. M. (1999). Cutoff criteria for fit indexes in covariance structure analysis: Conventional criteria versus new alternatives. Structural Equation Modeling, 6, 1-55.

Jessor, R. (Ed.). (1998). New Perspectives on Adolescent Risk Behavior. Cambridge, United Kingdom: Cambridge University Press.

Jessor, R., Van Den Bos, J., Vanderryn, J., Costa, F., \& Turbin, M. (1995). Protective factors in adolescent problem behavor: moderator effects and developmental change. Developmental Psychology, 31(6), 923-933.

Jessor, R., Turbin, M. S., Costa, F. M., Dong, Q., Zhang, H., \& Wang, C. (2003). Adolescent Problem Behavior in China and the United States: A Cross-National. Study of Psychosocial Protective Factors. Journal of Research on Adolescence, 13(3), 329-360.

Klem, L. (2000). Structural equation modeling. In L. G. Grimm \& P. R. Yarnold (Eds.), Reading and understanding multivariate statistics (pp. 227-257). Washington, DC: American Psychological Association.

Kline, R. B. (2005). Mutiple-Sample SEM. In Principles and Practice of Structural Equation Modeling; The Guilford Press: New York, New York; pp. 289-311.

Kumpfer, K., Olds, D., Alexander, J., Zucker, R., \& Gary, L. (1998). Family etiology of youth problems. Drug Abuse Prevention Through Family Interventions, 177, 42-77.

Lam, C. M., Lam, M. C., Shek, D. T. L., \& Tang, V. M. Y. (2004). Coping with economic disadvantage. A qualitative study of Chinese adolescents from low-income families. International journal of adolescent medicine and health, 16(4), 343-57. Retrieved from http://www.ncbi.nlm.nih.gov/pubmed/15712972

Leary, M. R., Schreindorfer, L. S., \& Haupt, A. L. (1995). The Role of Low Self-Esteem in Emotional and Behavioral Problems: Why is Low Self-Esteem Dysfunctional? Journal of Social and Clinical Psychology, 14(3), 297-314. doi:10.1521/jscp.1995.14.3.297

Lee, T. Y., Shek, D. T., \& Kwong, W. M. (2007). Chinese approaches to understanding and building resilience in at-risk children and adolescents. Child Adolesc Psychiatr Clin N Am, 16(2), 377-392, ix.

Liu, X., Kurita, H., Uchiyama, M., Okawa, M., Liu, L., \& Ma, D. (2000). Life events, locus of control, and behavioral problems among Chinese adolescents. J Clin Psychol, 56(12), 1565-1577.

Liu, X., Tein, J. Y., \& Zhao, Z. (2004). Coping strategies and behavioral/emotional problems among Chinese adolescents. Psychiatry Res, 126(3), 275-285.

Loeber, R., Slot, N. W., \& Stouthamer-Loeber, M. (Eds.). (2008). A cumulative developmental model of risk and promotive factors. . Farnham: Ashgate.

Luthar, S. S., \& Cicchetti, D. (2000). The construct of resilience: implications for interventions and social policies. Development and Psychopathology, 12, 857-885. 
Ma, X.; Yao, Y.; Zhao, X. (2013). Prevalence of Behavioral Problems and Related Family Functioning among Middle School Students in an Eastern City of China. Asia-Pacific psychiatry: official journal of the Pacific Rim College of Psychiatrists, 5, E1-8.

Mak, K.-K.; Ho, S.-Y.; Thomas, G. N.; Schooling, C. M.; McGhee, S. M.; Lam, T.-H. Family Structure, Parent-Child Conversation Time and Substance Use among Chinese Adolescents. BMC public health 2010, 10, 503.

Moos, R. H., \& Moos, D. S. (1981). Family Environment Scale Manual. Palo Alto, CA: Consulting Psychologists.

Nash, S. G., McQueen, A., \& Bray, J. H. (2005). Pathways to adolescent alcohol use: family environment, peer influence, and parental expectations. J Adolesc Health, 37(1), 19-28.

Newcomb, M. D., \& Felix-Ortiz, M. (1992). Multiple protective and risk factors for drug use and abuse: cross-sectional and prospective findings. J Pers Soc Psychol, 63(2), 280-296.

Newcomb, M. D., Huba, G. J., \& Bentler, P. M. (1986). Determinants of sexual and dating behaviors among adolescents. J Pers Soc Psychol, 50(2), 428-438.

Ostaszewski, K., \& Zimmerman, M. A. (2006). The effects of cumulative risks and promotive factors on urban adolescent alcohol and other drug use: a longitudinal study of resiliency. Am J Community Psychol, 38(3-4), 237-249.

Peng, L., Zhang, J., Li, M., Li, P., Zhang, Y., Zuo, X., ... Xu, Y. (2012). Negative life events and mental health of Chinese medical students: the effect of resilience, personality and social support.

Psychiatry research, 196(1), 138-41. doi:10.1016/j.psychres.2011.12.006

Petraitis, J., Flay, B. R., \& Miller, T. Q. (1995). Reviewing theories of adolescent substance use: organizing pieces in the puzzle. Psychological bulletin, 117(1), 67-86. Retrieved from http://www.ncbi.nlm.nih.gov/pubmed/7870864

Prentice, D. A.; Miller, D. T. (1992). When Small Effects Are Impressive. Psychological Bulletin, 112, $160-164$.

Procidano, M. E., \& Heller, K. (1983). Measures of perceived social support from friends and from family: three validation studies. Am J Community Psychol, 11(1), 1-24.

Raykov, T., Tomer, A., \& Nesselroade, J. R. (1991). Reporting structural equation modeling results in Psychology and Aging: some proposed guidelines. Psychol Aging, 6(4), 499-503.

Repetto, P. B., Zimmerman, M. A., \& Caldwell, C. H. (2004a). A longitudinal study of the relationship between depressive symptoms and alcohol use in a sample of inner-city black youth. Journal of Studies on Alcohol, 65, 169-178. Retrieved from

http://www.jsad.com/jsad/article/A_Longitudinal_Study_of_the_Relationship_between_Depressi ve_Symptoms_and_Al/1082.html

Repetto, P. B., Zimmerman, M. A., \& Caldwell, C. H. (2004b). A longitudinal study of the relationship between depressive symptoms and alcohol use in a sample of inner-city black youth. Journal of studies on alcohol, 65(2), 169-178. Retrieved from http://www.ncbi.nlm.nih.gov/pubmed/15151346 
Repetto, P. B., Zimmerman, M. A., \& Caldwell, C. H. (2008). A Longitudinal Study of Depressive Symptoms and Marijuana Use in a Sample of Inner-City African Americans. Journal of Research on Adolescence, 18(3), 421-447. doi:10.1111/j.1532-7795.2008.00566.x

Rutter, M. (1985). Resilience in the face of adversity. Protective factors and resistance to psychiatric disorder. Br J Psychiatry, 147, 598-611.

Rutter, M. (1987). Psychosocial resilience and protective mechanisms. Am J Orthopsychiatry, 57(3), 316331.

Rigby, K., \& Cox, I. (1996). The contribution of bullying at school and low self-esteem to acts of delinquency among Australian teenagers. Personality and Individual Differences, 21(4), 4-7.

Sameroff, A., Gutman, L. M., \& Peck, S. C. (2003). Adaptation among youth facing multiple risks: Prospective research findings. In S. S. Luthar (Ed.), Resilience and Vulnerability: Adaptation in the Context of Childhood. (pp. 364-391). New York: Cambridge University Press. Retrieved from http://dx.doi.org/10.1017/CBO9780511615788.017

Sameroff, A. J., \& Rosenblum, K. L. (2006). Psychosocial constraints on the development of resilience. Annals of the New York Academy of Sciences, 1094, 116-24. doi:10.1196/annals.1376.010

Schmeelk-cone, K. H., Zimmerman, M. A., \& Abelson, J. L. (2003). The Buffering Effects of Active Coping on the Relationship Between SES and Cortisol among African American young adults. Behavioral Medicine, 29(2), 85-94. doi:10.1080/08964280309596061

Shek, D. T. (1997). Family environment and adolescent psychological well-being, school adjustment, and problem behavior: a pioneer study in a Chinese context. J Genet Psychol, 158(1), 113-128.

Shek, D. T. L.(1999) Perceptions of Family Functioning among Chinese Parents and Their Adolescent Children. The American Journal of Family Therapy, 27, 303-314.

Shek, D. T. (2006a). Construction of a positive youth development program in Hong Kong. Int J Adolesc Med Health, 18(3), 299-302.

Shek, D. T. (2006b). Perceived parent-child relational qualities and parental behavioral and psychological control in Chinese adolescents in Hong Kong. Adolescence, 41(163), 563-581.

Shek, D. T. (2006c). Drop in Family Harmony in Hong Kong: An Ecological Analysis and Related Research. Paper presented at the Conference on Strengthening Hong Kong's Families: Awareness, Commitment and Action.

Shek, D. T., \& Lee, B. M. (2004). "Non-engaged" young people in Hong Kong: key statistics and observations. Int J Adolesc Med Health, 16(2), 145-163.

Shek, D. T. (2007). Tackling Adolescent Substance Abuse in Hong Kong: Where We Should and Should Not Go. The Scientific World Journal, 7, 2021-2030.

Simons-Morton, B. G., Hartos, J. L., \& Haynie, D. L. (2004). Prospective analysis of peer and parent influences on minor aggression among early adolescents. Health Educ Behav, 31(1), 22-33. 
Stacy, A. W., Newcomb, M. D., \& Bentler, P. M. (1992). Interactive and higher-order effects of social influences on drug use. J Health Soc Behav, 33(3), 226-241.

Stein, J. A., Newcomb, M. D., \& Bentler, P. M. (1986). Stability and change in personaility: A longitudinal study from early adolescence to young adulthood. Journal of Research in Personality, 20, 276-291.

Stoddard, S. A., Whiteside, L., Zimmerman, M. A., Cunningham, R. M., Chermack, S. T., \& Walton, M. A. (2012). The Relationship Between Cumulative Risk and Promotive Factors and Violent Behavior Among Urban Adolescents. Am J Community Psychol.

Tompkins, T. L., Hockett, A. R., Abraibesh, N., \& Witt, J. L. (2011). A closer look at co-rumination: Gender, coping, peer functioning and internalizing/externalizing problems. J Adolesc.

Van der Laan, A. M., Veenstra, R., Bogaerts, S., Verhulst, F. C., \& Ormel, J. (2010). Serious, minor, and non-delinquents in early adolescence: the impact of cumulative risk and promotive factors. The TRAILS study. J Abnorm Child Psychol, 38(3), 339-351.

Veronneau, M. H., \& Dishion, T. J. (2010). Predicting change in early adolescent problem behavior in the middle school years: a mesosystemic perspective on parenting and peer experiences. $J$ Abnorm Child Psychol, 38(8), 1125-1137.

Wang, D. (2006). Study of Juvenile Delinquency and Juvenile Protection in the People's Republic of China. Crime \& Justice International, 22(94), 4-13.

Wen, X., Chen, W., Muscat, J. E., Qian, Z., Lu, C., Zhang, C., et al. (2007). Modifiable family and school environmental factors associated with smoking status among adolescents in Guangzhou, China. Prev Med, 45(2-3), 189-197.

Wills, T. A., Vaccaro, D., \& McNamara, G. (1992). The role of life events, family support, and competence in adolescent substance use: a test of vulnerability and protective factors. Am J Community Psychol, 20(3), 349-374.

Wong, D. S. W. (2001). Changes in Juvenile Justice in China. Youth \& Society, 32(4), 492-509. doi:10.1177/0044118X01032004005

Wong, L., \& Mok, K. (1995). The reform and the changing social context. In L.Wong, \& S.MacPherson (Eds.), Social change and social policy in contemporary China (pp. 1-26). Aldershot, England: Avebury.

Xiong, Y.(2009) Social Change and Social Policy in China: National Adaptation to Global Challenge. International Journal of Japanese Sociology, 18, 33-44.

Youngblade, L. M., Theokas, C., Schulenberg, J., Curry, L., Huang, I. C., \& Novak, M. (2007). Risk and promotive factors in families, schools, and communities: a contextual model of positive youth development in adolescence. Pediatrics, 119 Suppl 1, S47-53.

Yu, X.-N., Lau, J. T. F., Mak, W. W. S., Zhang, J., \& Lui, W. W. S. (2011). Factor structure and psychometric properties of the Connor-Davidson Resilience Scale among Chinese adolescents. Comprehensive psychiatry, 52(2), 218-24. doi:10.1016/j.comppsych.2010.05.010 
Zimmerman, M. A., Bingenheimer, J. B., \& Notaro, P. C. (2002). Natural mentors and adolescent resiliency: a study with urban youth. Am J Community Psychol, 30(2), 221-243.

Zimmerman, M. a, Stoddard, S. a, Eisman, A. B., Caldwell, C. H., Aiyer, S. M., \& Miller, A. (2013). Adolescent Resilience: Promotive Factors That Inform Prevention. Child development perspectives, 7(4), 215-220. doi:10.1111/cdep.12042 


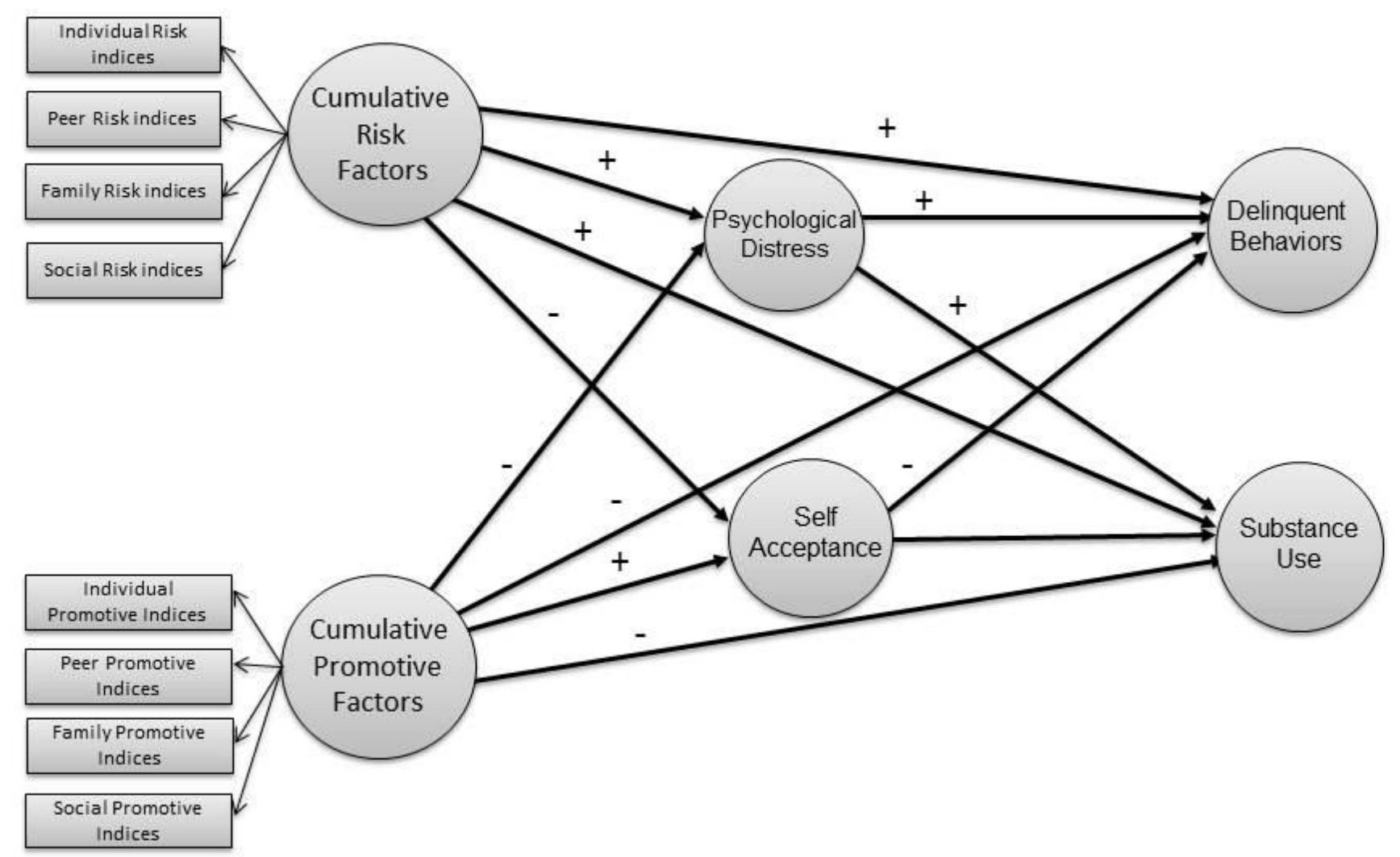

Figure 1. Theoretical Model of the Effects of Cumulative Risks and Promotive Factors on Problem Behaviors among Chinese Teens. 


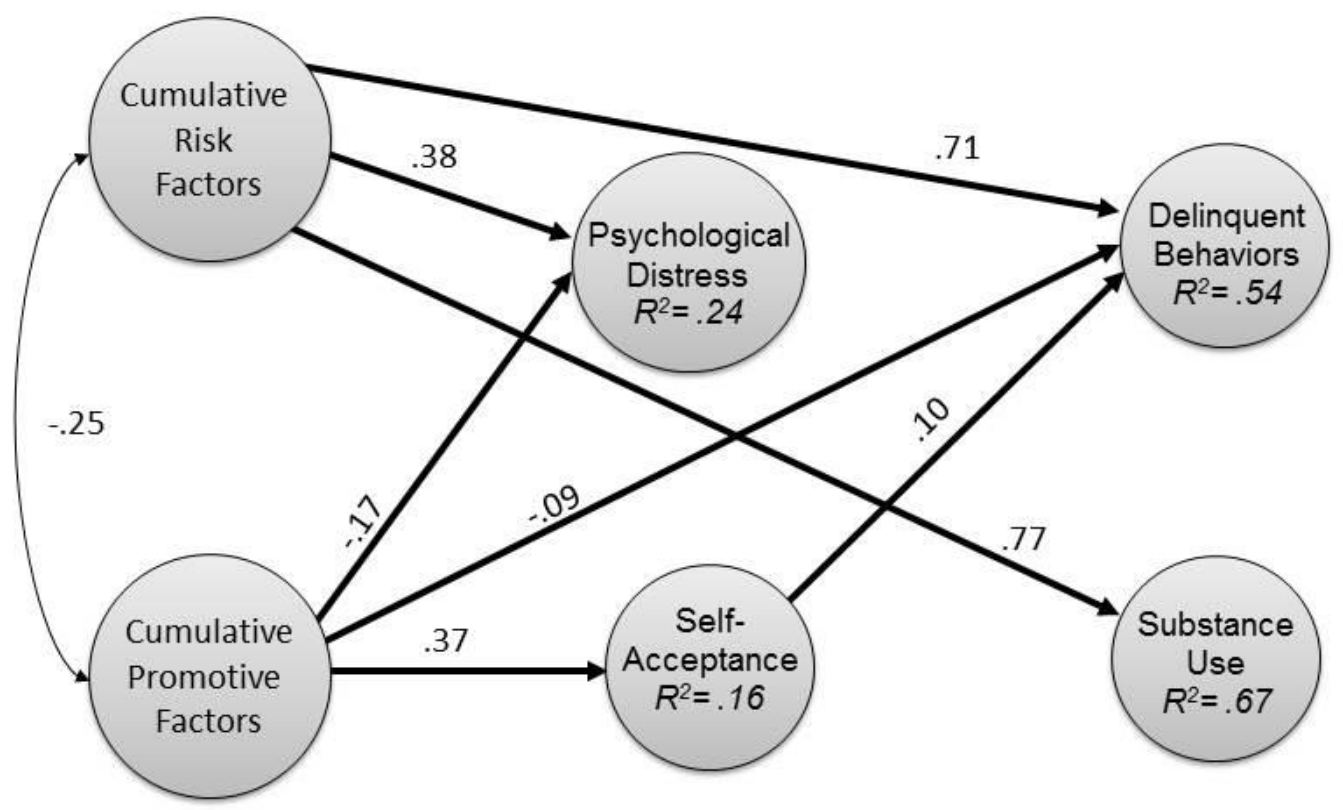

Figure 2. Chinese Teen's Problem Behaviors as a Result of Cumulative Risks and Promotive Factors. Yuan-Bentler scaled $\chi 2$ (152, $\mathrm{n}$ $=1349)=491.05(\mathrm{p}<.001)$, Bentler-Bonett NFI $=.89, \mathrm{NNFI}=.89, \mathrm{CFI}=.92, \mathrm{RMSEA}=.041$. The independent factors were allowed to covary. Residuals between endogenous latent factors were also allowed to covary. All paths with solid lines are statistically significant at $\mathrm{p}<.05$. Controlled by school grade, gender, father's education and mother's education. 


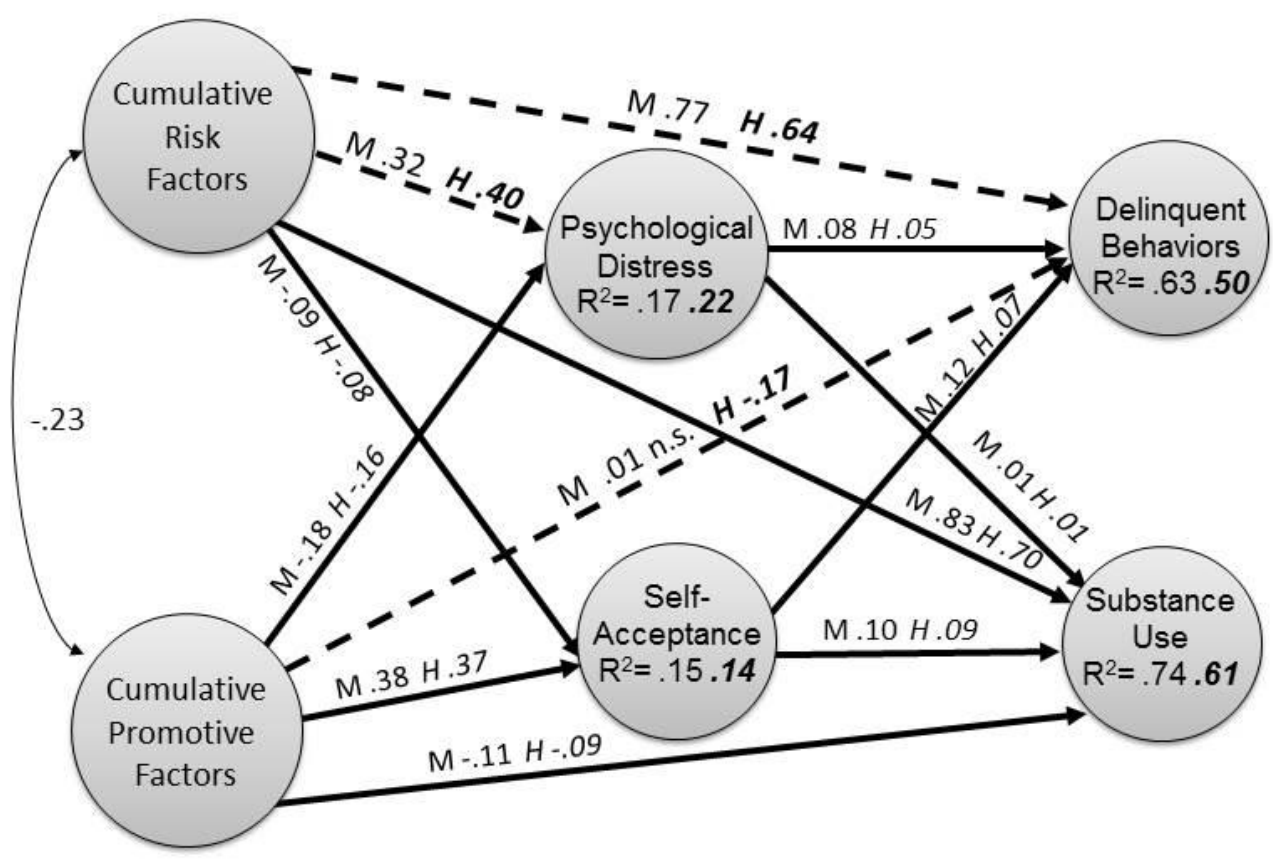

Figure 3. Multiple Groups Comparison for high school vs. middle school adolescents. Yuan-Bentler scaled $\chi^{2}$ (302, n middle school $=601, \mathrm{n}$ high school $=752)=674.86, \mathrm{p}<0.01$, and with NFI $=0.85, \mathrm{NNFI}=0.89, \mathrm{CFI}=0.91, \mathrm{RMSEA}=0.043$. After releasing the constrains: Yuan-Bentler scaled $\chi 2(300, \mathrm{n}$ middle school $=601, \mathrm{n}$ high school $=752)=657.50, \mathrm{p}<0.001$, and with NFI $=0.86$, NNFI $=0.90, \mathrm{CFI}=0.92, \mathrm{RMSEA}=0.042$. The independent factors were allowed to covary. Residuals between endogenous latent factors were also allowed to covary. All paths shown are statistically significant at $p<.05$. The dashed lines are the paths that were modified by school grades. The bold numbers indicate coefficients for High School group. 
Table 1

Descriptive statistics and individual measures for cumulative risk factors

\begin{tabular}{|c|c|c|c|c|}
\hline $\begin{array}{l}\text { Risk factors (number } \\
\text { of items) }\end{array}$ & Mean & SD & $\alpha$ & Sample Item (type of scale used) \\
\hline $\begin{array}{l}\text { Individual/behavioral } \\
\text { Perceived stress (5) }\end{array}$ & 2.33 & .82 & .77 & $\begin{array}{l}\text { feel nervous and stressed out ( } 5 \text {-pt Likert, } 1 \\
=\text { never, } 5=\text { very often) }\end{array}$ \\
\hline $\begin{array}{l}\text { Being a victim of } \\
\text { violence ( } 3)\end{array}$ & 1.23 & .55 & .71 & $\begin{array}{l}\text { had someone threaten to hurt you during the last } \\
12 \text { months (5-pt Likert, } 1=0 \text { times, } 5=4+\text { times) }\end{array}$ \\
\hline $\begin{array}{l}\text { Peer } \\
\text { Friends use alcohol or } \\
\text { drugs (4) }\end{array}$ & 1.27 & .47 & .75 & $\begin{array}{l}\text { How many of your friends drink beer or wine at } \\
\text { least once a month }(5-\mathrm{pt} \text { Likert, } 1=\text { none, } 5=\text { all })\end{array}$ \\
\hline $\begin{array}{l}\text { Friends } \\
\text { cut/suspended/dropped } \\
\text { out of school (2) }\end{array}$ & 1.28 & .49 & .62 & $\begin{array}{l}\text { How many of your friends cut class-just don't } \\
\text { go }(5-\mathrm{pt} \mathrm{Likert,} 1=\text { none, } 5=\text { all })\end{array}$ \\
\hline $\begin{array}{l}\text { Friends aggressive or } \\
\text { delinquent behaviors } \\
\text { (4) }\end{array}$ & 1.21 & .41 & .72 & $\begin{array}{l}\text { How many of your friends get into fights }(5-\mathrm{pt} \\
\text { Likert, } 1=\text { none, } 5=\text { all })\end{array}$ \\
\hline $\begin{array}{l}\text { Parental/Familial } \\
\text { Alcohol and tobacco } \\
\text { use by parents }(3)\end{array}$ & 2.20 & .97 & .70 & $\begin{array}{l}\text { Does either of your parents get drunk ( } 5 \text {-pt } \\
\text { Likert, } 1=\text { never, } 5=\text { very often) }\end{array}$ \\
\hline $\begin{array}{l}\text { Misdeeds/Misconduct } \\
\text { by parents }\end{array}$ & 1.15 & .38 & .85 & $\begin{array}{l}\text { Does either of your parents carry a knife or } \\
\text { razor ( } 5 \text {-pt Likert, } 1=\text { never, } 5=\text { very often) }\end{array}$ \\
\hline $\begin{array}{l}\text { Social Contexts } \\
\text { Misdeeds/misconduct } \\
\text { by non-familial adults } \\
\text { in life of student (4) }\end{array}$ & 1.33 & .55 & .81 & $\begin{array}{l}\text { Not including your parents or the adults you live } \\
\text { with how many adults do you know who } \\
\text { threaten to hurt people ( } 5 \text {-pt Likert, } 1=\text { none, } \\
5=\text { all) }\end{array}$ \\
\hline $\begin{array}{l}\text { Alcohol use by non- } \\
\text { familial adults in life } \\
\text { of student (4) }\end{array}$ & 1.44 & .61 & .76 & $\begin{array}{l}\text { Not including your parents or the adults you live } \\
\text { with how many adults do you know who get } \\
\text { drunk at least once a month ( } 5 \text {-pt Likert, } \\
1=\text { none, } 5=\text { all) }\end{array}$ \\
\hline
\end{tabular}


Table 2

Descriptive statistics and individual measures for cumulative promotive factors

\begin{tabular}{|c|c|c|c|c|}
\hline $\begin{array}{l}\text { Promotive Factors } \\
\text { (number of items) }\end{array}$ & Mean & SD & $\alpha / \mathrm{r}$ & Sample Item (type of scale used) \\
\hline $\begin{array}{l}\text { Individual } \\
\text { Perceived control } \\
\text { respondent feels } \\
\text { s/he has over } \\
\text { personal life (8) }\end{array}$ & 2.96 & .86 & .87 & $\begin{array}{l}\text { In the last month, how often have you felt that you } \\
\text { were in control of your life ( } 5 \text {-pt Likert, } 1=\text { never, } \\
5=\text { very often) }\end{array}$ \\
\hline $\begin{array}{l}\text { Orientation toward } \\
\text { the future }(2)\end{array}$ & 3.53 & $\begin{array}{l}1.1 \\
5\end{array}$ & .78 & $\begin{array}{l}\text { I think a lot about my future job (5-pt Likert, } 1=\text { not } \\
\text { true, } 5=\text { very true) }\end{array}$ \\
\hline $\begin{array}{l}\text { Peer } \\
\text { Friends' support (5) }\end{array}$ & 3.61 & .84 & .84 & $\begin{array}{l}\text { I rely on my friends for emotional support }(5-\mathrm{pt} \\
\text { Likert, } 1=\text { not true, } 5=\text { =very true })\end{array}$ \\
\hline $\begin{array}{l}\text { Friends Positive } \\
\text { influence ( } 3)\end{array}$ & 3.09 & .81 & .56 & $\begin{array}{l}\text { How many of your friends take part in student } \\
\text { council }(5-\mathrm{pt} \text { Likert, } 1=\text { none, } 5=\text { all })\end{array}$ \\
\hline $\begin{array}{l}\text { Parental/Familial } \\
\text { Parental support } \\
\text { (10) }\end{array}$ & 3.51 & .80 & .87 & $\begin{array}{l}\text { My father enjoys hearing about what I think }(5-\mathrm{pt} \\
\text { Likert, } 1=\text { not true, } 5=\text { very true })\end{array}$ \\
\hline $\begin{array}{l}\text { Parent supervision } \\
\text { of student's } \\
\text { activities }(6)\end{array}$ & 3.81 & .98 & .88 & $\begin{array}{l}\text { I tell my parents who I'm going to be with before I } \\
\text { go out (5-pt Likert, } 1=\text { never, } 5=\text { always) }\end{array}$ \\
\hline $\begin{array}{l}\text { Social Contexts } \\
\text { Neighborhood } \\
\text { monitoring (3) }\end{array}$ & 3.84 & $\begin{array}{l}1.0 \\
1\end{array}$ & .82 & $\begin{array}{l}\text { If I were to do something wrong and neighbors or } \\
\text { other adults in my community were to see, they } \\
\text { would probably tell my parents (5-pt Likert, } 1=\text { yes } \\
\text { definitely, } 5=\text { definitely not) }\end{array}$ \\
\hline $\begin{array}{l}\text { In-school and out- } \\
\text { school activities (6) }\end{array}$ & $\begin{array}{l}\text { Sum of } \\
\text { Z- } \\
\text { scores }\end{array}$ & 5.2 & .96 & $\begin{array}{l}\text { In the last year, have you participated in any } \\
\text { school clubs, societies, sports or other } \\
\text { extracurricular activities (for example } \\
\text { cheerleading, student council, marching band, etc.) } \\
\text { (yes or no) How often did you attend this activity } \\
\text { (4-pt Likert, } 1=\text { hardly ever, } 4=\text { most of the time) }\end{array}$ \\
\hline
\end{tabular}


Table 3

Means and standard deviations of outcome variables by school grades

\begin{tabular}{|c|c|c|}
\hline Key Variables & $\begin{array}{l}\text { Middle School } \\
\text { Mean (S.D.) }\end{array}$ & $\begin{array}{l}\text { High School } \\
\text { Mean (S.D.) }\end{array}$ \\
\hline Individual Risk Variables ${ }^{l}$ & $-0.21(1.56)$ & $0.17(1.42)$ \\
\hline Peer Risk Variables ${ }^{1}$ & $-0.46(2.13)$ & $0.33(2.75)$ \\
\hline Family Risk Variables ${ }^{1}$ & $-0.20(1.43)$ & $0.16(1.68)$ \\
\hline Community Risk Variables ${ }^{1}$ & $-0.25(1.57)$ & $0.19(1.82)$ \\
\hline Individual Promotive variables ${ }^{l}$ & $-0.05(1.54)$ & $0.05(1.45)$ \\
\hline Peer Promotive variables ${ }^{l}$ & $0.18(1.63)$ & $-0.14(1.43)$ \\
\hline Family Promotive variables ${ }^{l}$ & $0.01(1.72)$ & $-0.01(1.55)$ \\
\hline Community Promotive variables ${ }^{l}$ & $0.22(1.48)$ & $-0.17(1.42)$ \\
\hline \multicolumn{3}{|l|}{ Psychological distress } \\
\hline Anxiety (1-5) & $1.59(0.74)$ & $1.88(0.91)$ \\
\hline Depression (1-5) & $1.62(0.79)$ & $1.92(0.90)$ \\
\hline Self-acceptance (1-5) & $3.45(0.83)$ & $3.27(0.87)$ \\
\hline \multicolumn{3}{|l|}{ Delinquency } \\
\hline Non-Violent (1-5) & $1.06(0.17)$ & $1.12(0.43)$ \\
\hline Violent (1-5) & $1.10(0.33)$ & $1.14(0.44)$ \\
\hline \multicolumn{3}{|l|}{ Substance Use } \\
\hline Smoking in past 30 days $(1-5)$ & $1.17(0.56)$ & $1.34(0.82)$ \\
\hline Alcohol Use in past 30 days $(1-7)$ & $1.26(0.76)$ & $1.41(0.84)$ \\
\hline
\end{tabular}


Table 4

Matrix of Correlations among Risk Variables and Outcome Variables

\begin{tabular}{|c|c|c|c|c|c|c|c|c|c|c|c|}
\hline Subscale & $\begin{array}{l}1 . \\
\text { IRV }\end{array}$ & $\begin{array}{l}2 . \\
\text { PRV }\end{array}$ & $\begin{array}{l}3 . \\
\text { FRV }\end{array}$ & $\begin{array}{l}4 . \\
\text { CRV }\end{array}$ & $\begin{array}{l}5 . \\
\text { Anxiety }\end{array}$ & $\begin{array}{l}6 . \\
\text { Depression }\end{array}$ & $\begin{array}{l}7 . \\
\text { Self } \\
\text { Acceptance }\end{array}$ & $\begin{array}{l}8 . \\
\text { NVD }\end{array}$ & $\begin{array}{l}9 . \\
\text { Violent } \\
\text { Behavior }\end{array}$ & $\begin{array}{l}10 . \\
\text { Smoking }\end{array}$ & $\begin{array}{l}11 . \\
\text { Alcohol } \\
\text { Use }\end{array}$ \\
\hline $\begin{array}{l}\text { 1.Individual } \\
\text { Risk Variables } \\
\text { (IRV) }\end{array}$ & 1.00 & & & & & & & & & & \\
\hline $\begin{array}{l}\text { 2. Peer Risk } \\
\text { Variables } \\
\text { (PRV) }\end{array}$ & $.28 * *$ & 1.00 & & & & & & & & & \\
\hline $\begin{array}{l}\text { 3. Family Risk } \\
\text { Variables } \\
\text { (FRV) }\end{array}$ & $.34 * *$ & $.29 * *$ & 1.00 & & & & & & & & \\
\hline $\begin{array}{l}\text { 4. Community } \\
\text { Risk Variables } \\
\text { (CRV) }\end{array}$ & $.34 * *$ & $.49 * *$ & $.47 * *$ & 1.00 & & & & & & & \\
\hline 5. Anxiety & $.52 * *$ & $.17^{* *}$ & $.27 * *$ & $.22 * *$ & 1.00 & & & & & & \\
\hline 6. Depression & $.54 * *$ & $.21 * *$ & $.29 * *$ & $.23^{*}$ & $.82 * *$ & 1.00 & & & & & \\
\hline $\begin{array}{l}\text { 7. Self- } \\
\text { acceptance }\end{array}$ & $-.24 * *$ & $-.06 *$ & $-.09 *$ & $-.07 *$ & $-.32 * *$ & $-.38 * *$ & 1.00 & & & & \\
\hline $\begin{array}{l}\text { 8. Non-Violent } \\
\text { Delinquency } \\
\text { (NVD) }\end{array}$ & $.33 * *$ & $.27^{* *}$ & $.33 * *$ & $.39 * *$ & $.21 * *$ & $.24 * *$ & $-.06 *$ & 1.00 & & & \\
\hline $\begin{array}{l}\text { 9. Violent } \\
\text { Behavior }\end{array}$ & $.41 * *$ & $.40 * *$ & $.35 * *$ & $.50 * *$ & $.21 * *$ & $.24 * *$ & -.05 & $.65 * *$ & 1.00 & & \\
\hline 10.Smoking & $.25 * *$ & $.35 * *$ & $.31 * *$ & $.40 * *$ & $.13^{* *}$ & $.17^{* *}$ & $-.07 * *$ & $.21 * *$ & $.37 * *$ & 1.00 & \\
\hline 11.Alcohol Use & $.24 * *$ & $.33 * *$ & $.29 * *$ & $.39 * *$ & $.17 * *$ & $.19 * *$ & -.02 & $.20 * *$ & $.28 * *$ & $.41 * *$ & 1.00 \\
\hline
\end{tabular}

**.Correlation is significant at the 0.01 level (2-tailed).

* .Correlation is significant at the 0.05 level (2-tailed). 
Table 5

Matrix of Correlations among Promotive Variables and Outcome Variables

\begin{tabular}{|c|c|c|c|c|c|c|c|c|c|c|c|}
\hline Subscale & $\begin{array}{l}1 . \\
\text { IPV }\end{array}$ & $\begin{array}{l}2 . \\
\text { PPV }\end{array}$ & $\begin{array}{l}3 . \\
\text { FPV }\end{array}$ & $\begin{array}{l}4 . \\
\text { CPV }\end{array}$ & $\begin{array}{l}5 . \\
\text { Anxiety }\end{array}$ & $\begin{array}{l}6 . \\
\text { Depression }\end{array}$ & $\begin{array}{l}7 . \\
\text { Self } \\
\text { Acceptance }\end{array}$ & $\begin{array}{l}8 . \\
\text { NVD }\end{array}$ & $\begin{array}{l}9 . \\
\text { Violent } \\
\text { Behavior }\end{array}$ & $\begin{array}{l}10 . \\
\text { Smoking }\end{array}$ & $\begin{array}{l}11 . \\
\text { Alcohol } \\
\text { Use }\end{array}$ \\
\hline $\begin{array}{l}\text { 1. Individual Pro. } \\
\text { Variables } \\
\text { (IPV) }\end{array}$ & 1.00 & & & & & & & & & & \\
\hline $\begin{array}{l}\text { 2. Peer Pro. } \\
\text { Variables } \\
\text { (PPV) }\end{array}$ & $.25^{* *}$ & 1.00 & & & & & & & & & \\
\hline $\begin{array}{l}\text { 4. Community } \\
\text { Pro. Variables } \\
\text { (CPV) }\end{array}$ & $.13^{* *}$ & $.20 * *$ & $.21 * *$ & 1.00 & & & & & & & \\
\hline 5. Anxiety & -.04 & $-.07 * *$ & $-.10 * *$ & $-.08 * *$ & 1.00 & & & & & & \\
\hline $\begin{array}{l}\text { 9. Violent } \\
\text { Behavior }\end{array}$ & -.03 & $-.12 * *$ & $-.17 * *$ & $-.08 * *$ & $.21 * *$ & $.24^{* *}$ & -.05 & $.65^{* *}$ & 1.00 & & \\
\hline 10.Smoking & 0.01 & $-.12 * *$ & $-.14^{* *}$ & $-.08 * *$ & $.13^{* *}$ & $.17^{* *}$ & $-.07 * *$ & $.21 * *$ & $.37^{* *}$ & 1.00 & \\
\hline 11.Alcohol Use & 0.03 & $-.06^{*}$ & $-.17 * *$ & $-.07 * *$ & $.17^{* *}$ & $.19 * *$ & -.02 & $.20 * *$ & $.28^{* *}$ & $.41^{* *}$ & 1.00 \\
\hline
\end{tabular}

**.Correlation is significant at the 0.01 level (2-tailed).

* .Correlation is significant at the 0.05 level (2-tailed). 